Voix et Images

voixetimages

\title{
Imbuvables, les Fées?... Pour qui?
}

\section{Bernard Andrès}

Volume 4, numéro 3, avril 1979

Louis-Philippe Hébert

URI : https://id.erudit.org/iderudit/200177ar

DOI : https://doi.org/10.7202/200177ar

Aller au sommaire du numéro

Éditeur(s)

Les Presses de l'Université du Québec

ISSN

0318-9201 (imprimé)

1705-933X (numérique)

Découvrir la revue

Citer cet article

Andrès, B. (1979). Imbuvables, les Fées?... Pour qui? Voix et Images, 4(3),

540-541. https://doi.org/10.7202/200177ar d'utilisation que vous pouvez consulter en ligne.

https://apropos.erudit.org/fr/usagers/politique-dutilisation/ 


\section{Imbuvables, les Fées?... Pour qui?}

La rentrée théâtrale a été marquée par un événement de la scène qui, chacun l'a observé, a vite débordé le domaine du spectacle... ou du moins l'a déplacé du théâtre à la rue et de la rue à la-Cour. La genèse des Fées ont soif témoigne elle-même de ce déplacement sur la place publique. On se rappelle la polémique sur la censure préalable exercée par le Conseil des arts de Montréal qui refusait de subventionner la pièce, exigeant des directeurs de théâtre de soumettre à l'avenir les textes à subventionner ${ }^{1}$. D'une prise de position à l'autre, chacun s'efforçant de dévoiler des extraits, les Fées s'en sont trouvées déflorées avant même la première ${ }^{2}$. Je passe sur la teneur de cette polémique dont le lecteur se fera une idée en parcourant le dossier de presse publié avec la pièce par la librairie des Femmes d'ici (à l'heure où j'écris ces lignes, l'injonction provisoire vient d'être levée: seule plane encore la menace d'un jugement en appel). Il faut surtout retenir la levée de bouclier de l'Association des directeurs de théâtre (A.D.T.) qui a refusé les subventions dudit Conseil tant que la censure indirecte aurait cours (à noter la saveur variée des commentaires et déclarations de principe des directeurs artistiques, du T.N.M. au théâtre d'Aujourd'hui, en passant par le contestataire théâtre du Rideau vert...).

Mais avec la représentation proprement dite (l'adverbe agacera les censeurs), on est passé de la place publique à la voie publique. Un dimanche de novembre, à l'heure de la messe, le débat était ouvert sur la 
Catherine où la ronde des Fermières et des Jeunes Chrétiens pour une Civilisation canadienne (ou l'inverse), manifestait au son de l'ave Maria contre le "mépris et la vulgarité " des Fées (dixit Mgr Paul Grégoire). Pour eux les Fées étaient imbuvables et ils faisaient tout pour faire passer leur protestation sur la voie publique pour un écho de la vox populi. Dieu était de leur côté, ainsi que le passé religieux du Québec. II n'en reste pas moins que leur action devant les tribunaux a privé une bonne partie du public de la liberté de se procurer le texte pendant un bon mois (et que seule une lectrice potentielle a jugé bon de s'en plaindre en haut lieu!):

Pendant ce temps, les éditions Dottini se flattaient d'inonder le marché avec la bible fasciste du gourou brésilien Plinio Corrêa de Oliveira, Révolution et contre-révolution: "Plus de 100000 copies déjà vendues", proclame la publication N.S.J.C. (!) en remerciant “vivement les Jeunes Canadiens pour une Civilisation chrétienne qui ont participé activement à la réalisation de cet ouvrage ${ }^{3}$ ". On sait par ailleurs qu'une recrudescence analogue d'obscurantisme se manifeste en Ontario ${ }^{4}$. Une telle convergence d'indices ne peut qu'inquiéter le chroniqueur qu'on excusera ici de négliger le théâtre proprement dit pour des préoccupations à la fois plus vastes et plus urgentes puisqu'elles touchent au climat culturel et politique dont cette revue ne peut que rendre compte ${ }^{5}$.

Bernard Andrès

1. Précensure portant sur le canevas d'un texte qui n'est souvent lui-même, comme on le sait bien au théâtre, qu'une trace négligeable du phénomène de la représentation... Se trouve du coup évacué, sacrifié sur l'hôtel de la décence, tout le travail de J.-L. Bastien à la mise en scène (Cf. le Devoir du 17/11/ 1978: «MM. les censeurs, coupez les premiers $)$.

2. Je tente ailleurs d'aborder le problème de la réception de cette pièce : "L'intellectuel croit-il aux fées ? ou les enjeux d'une injonction " (le Devoir, 10 fév. 1979).

3. Plinio de Oliveira est ainsi présenté par l'éditeur : "Le Professeur Plinio Corrêa de Oliveira est né en 1908 à São Paulo, Brésil. Il est issu de grandes familles aristocratiques [...] Son grand-oncle [...] fut lui-même Premier ministre de Dom Pedro II, dernier empereur du Brésil. Très précoce et éminemment doué, le Professeur $P[\ldots] C[\ldots]$ de $O$ [...] parlait couramment sa langue maternelle à six mois et maîtrisait le français et l'allemand dès l'âge de quatre ans. II devint vite préoccupé par la grande crise politique, sociale et religieuse qui secoue la Civilisation chrétienne. On peut dire qu'à l'âge de sept ans, la base de presque tout ce qu'il a écrit et fait plus tard se dessinait déjà dans son âme "... A noter que les publications N.S.J.C. sont une filiale des éditions Paul Dottini Inc., au même titre semble-t-il que la collection "Tradition, Famille, Propriété" qui traque Moscou jusque dans les mouvements progressistes chrétiens (Développement et Paix), et nous met en garde contre le laisseraller dans: Québécois, la strappe glisse !...

4. Cf. l'article de Patricia Dumas dans le Devoir du 13/12/1978.

5. Il aurait surtout fallu parler de l'excellent Macbeth de Michel Garneau par le théâtre de la Manufacture. La revue Jeu $n^{\circ} \|$, y consacre un dossier dans sa livraison de printemps. 